\title{
Para comprender el impacto disruptivo de la covid-19, un análisis desde la crítica de la economía política
}

\author{
Understanding the disruptive impact of covid-19, \\ an analysis from the perspective of critical political economy
}

Guillermo Foladori*
Raúl Delgado Wise

ISSN IMPRESO 1870-7599 | ISSN RED CÓMPUTO 2448-7783 | 161-178

RECIBIDO 02/03/20 | ACEPTADO 26/03/20

Resumen. El propósito de este artículo es profundizar en torno a las causas e implicaciones de la pandemia covid-19. Busca develar el alcance y profundidad de su impacto disruptivo sobre la contradicción capital-trabajo. El artículo está organizado en dos apartados. En el primero, se abordan las causas que contribuyen al surgimiento y propagación de la pandemia. Allí se dilucidan las principales contradicciones y tendencias que subyacen al modus operandi del capitalismo contemporáneo y que dan cuenta del contexto particular en el que se disemina el virus. En el segundo apartado se analizan los efectos e implicaciones de la pandemia en la relación capital-trabajo asalariado. Si bien algunos de estos efectos son abordados en la literatura, nuestro análisis se centra en desentrañar la conexión profunda con la contradicción capital-trabajo, que es la esencia del régimen capitalista de producción.

Palabras clave: covid-19, capital-trabajo, fuerzas productivas, salud, crisis.

\begin{abstract}
The purpose of this article is to delve into the causes and implications of the covid-19 pandemic. It seeks to unravel the scope and depth of its disruptive impact on the capital-labor contradiction. The article is organized in two sections. In the first, the causes that contribute to the emergence and spread of the pandemic are addressed. Our aim is to elucidate the main contradictions and tendencies that underlie the modus operandi of contemporary capitalism and that account for the particular context in which the virus spreads. In the second section, the effects and implications of the pandemic on the capital-wage labor relationship are analyzed. Although some of these effects are addressed in the literature, our analysis focuses on unraveling its deep connection with the capital-labor contradiction, which is the essence of the capitalist production regime.
\end{abstract}

Keywords: covid-19, capital-labor, productive forces, health, crisis.

* Uruguayo. Unidad Acádemica en Estudios del Desarrollo, Universidad Autónoma de Zacatecas, México. Correo-e: gfoladori@gmail.com

** Mexicano. Unidad Acádemica en Estudios del Desarrollo, Universidad Autónoma de Zacatecas, México. Correo-e: rdwise@uaz.edu.mx 


\section{Introducción}

Los científicos se debaten sobre las causas de la pandemia de la covid-19.1 Hablan del consumo de animales silvestres infectados, de animales criados en escala industrial cuyo hacinamiento facilita las enfermedades contagiosas, del escape del virus de un laboratorio de alto confinamiento, de cambios en los ecosistemas debidos al monocultivo y la deforestación que impide la resiliencia, de la expansión de químicos tóxicos provocando mutaciones y fragilizando al organismo humano, de la expansión de radiaciones y ondas electromagnéticas derivada de las Tecnologías de la Información y la Comunicación (TIC) que enferma el tejido celular, o del consumo masivo de antibióticos y vacunas que reduce la inmunidad humana. Sea cual sea la explicación de la causa inmediata del fenómeno, hay algo que tienen en común: se trata de una crisis manifiesta de salud que alcanza, aunque en diferente grado, a todas las clases sociales, grupos étnicos, ideologías y sexos, y que ataca con mayor saña a los adultos mayores por su debilidad etaria intrínseca. ${ }^{2}$ Aunque en apariencia la enfermedad no distingue entre sus víctimas, las crisis ambientales o de salud nunca golpean a todos por igual, inclusive aquellas crisis que tienen su origen en eventos «externos», como huracanes, tsunamis u otros (Sarewitz y Pielke, 2001; Foladori, 2005a). En similar tenor, las posibilidades de contagio y curación de enfermedades infecciosas también son muy diferentes en función de múltiples factores que se resumen en el nivel de vida (McKeown, 1991) y en las condiciones de desarrollo económico (Brown, 1987).

Para que se produzca una enfermedad a nivel individual o personal se requiere la convergencia de dos elementos: una causa externa y una condición interna al organismo. En el caso que nos ocupa la causa externa es un virus, el SARS-CoV-2, y la causa interna son las condiciones de salud de la persona. Sin embargo, no estamos tratando con una enfermedad, sino con una pandemia. La diferencia no es sólo cuantitativa sino de orden multidimensional, porque al extenderse la enfermedad como epidemia primero y pandemia después, las condiciones internas

${ }^{1}$ La Organización Mundial de la Salud comenzó a llamar covid-19 a la enfermedad del coronavirus, el 19 corresponde al año de los primeros casos detectados. Con ello se evitaban nombres que pudieran incitar la xenofobia y preconcepto.

${ }^{2}$ Entrada la tercera de abril de 2020 la cantidad de muertes por covid-19 pasaba los 107 mil casos a escala mundial (John Hopkins Coronavirus Resource Center, 2020). 
de las personas ya no son particulares, individuales, sino que son producto y resultado de las condiciones socioeconómicas y ambientales, de las condiciones de vida, donde causas internas y externas se imbrican.

El propósito de este artículo es profundizar en torno a las causas e implicaciones de la pandemia covid-19. Nos interesa, ante todo, develar el alcance y profundidad de su impacto disruptivo sobre la contradicción capital-trabajo. Para fines analíticos, el artículo se organiza en dos grandes apartados. En el primero, se abordan las causas que contribuyen al surgimiento y propagación de la pandemia. Debido a que existen numerosos artículos y libros que examinan esta cuestión, nuestro interés se centra en dilucidar las principales contradicciones y tendencias que subyacen al modus operandi del capitalismo contemporáneo y que dan cuenta del contexto particular en el que se disemina el virus. En el segundo apartado y como parte medular se analizan los efectos e implicaciones de la pandemia en la relación capital-trabajo asalariado. Si bien algunos de estos efectos están presentes en la literatura, nuestro análisis se propone desentrañar su conexión directa y más profunda con la contradicción esencial del capitalismo.

\section{Las causas de la pandemia: de la salud a la economía}

Epidemias y plagas derivadas de enfermedades infecciosas siempre han existido en la historia de la humanidad. Hay registros de ello previos, incluso, a la era cristiana (Jarus, 2020). No obstante, la enfermedad se presenta, expande y profundiza de diferentes maneras en un momento y en una sociedad determinada. Más allá de diversos factores, como el grado y cantidad de concentración de la población, las medidas sanitarias, el conocimiento de las causas reales del contagio, el nivel de salud de la población y el grado de desarrollo de los medios de contención, resulta fundamental desentrañar el contexto socio económico e histórico específico en el que cada contingencia sanitaria ocurre.

La pandemia de la covid-19 se da en condiciones de un contexto capitalista altamente desarrollado. Es sabido que el sistema capitalista presenta al menos tres tendencias generales que le son intrínsecas y que se retroalimentan dialécticamente: la ampliación de la división social del trabajo, la profundidad de la diferenciación e inequidad social, y el desarrollo de las fuerzas productivas (Rubin, 1972). A dos siglos y medio de la Revolución industrial, la profundización y expansión de aquellas tres tendencias puede visualizarse fácilmente en las 
cadenas productivas globales, donde para la fabricación de un producto participan decenas de empresas en muchos países simultáneamente; o en la distancia entre un puñado de multimillonarios que poseen más riqueza que varios países e incluso que regiones enteras del mundo con cientos de millones de habitantes; o en el grado de desarrollo de las fuerzas productivas donde la automatización ha hecho superflua la fuerza de trabajo en las industrias de vanguardia.

Si prestamos atención a la pandemia, aquellas tendencias se expresan de múltiples formas directamente conectadas con la enfermedad. Se manifiestan en la expansión ilimitada y globalizada de la producción y el mercado, que llega a borrar las barreras naturales que antaño contenían las epidemias. A ello se agrega un fuerte movimiento no sólo de mercancías, sino de personas que atraviesan fronteras nacionales y regionales para procurarse la subsistencia ante la falta de empleo, el despojo de tierras, la emergencia de conflictos bélicos, guerras imperiales y desastres naturales: las migraciones internacionales forzadas que caracterizan al capitalismo contemporáneo (Delgado, 2013). Pero no sólo se trasladan pobres y trabajadores, el turismo con millones de beneficiarios anuales ha sido también un sector económico de gran crecimiento en las últimas décadas (Dachary y Arnaiz, 2002). En este sentido, la creciente movilidad humana funge también como causa y consecuencia de los contagios.

Más aún, el contexto en el que se despliega la pandemia entraña una recomposición y profundización de la división social e internacional del trabajo que, a la vez que fracciona progresivamente las distintas fases de los procesos productivos y de servicios, las interconecta en términos productivos, comerciales y financieros. Derivado de las posibilidades abiertas por las TIC, se produce un desplazamiento de parte de los procesos productivos, comerciales y de servicios de las grandes corporaciones multinacionales, a través de operaciones outsourcing y procesos de subcontratación, hacia la periferia en busca de fuerza de trabajo barata y flexible (Foster et al., 2011; Delgado, 2017). Esto último ha propiciado la emergencia de una nueva división internacional del trabajo, donde la fuerza de trabajo de la periferia figura como una importante y cada vez más significativa mercancía (Delgado, 2013). Para finales de la primera década de este siglo al menos 40 por ciento del comercio mundial se asocia a operaciones de outsourcing, incluyendo subcontrataciones y comercio intrafirma entre filiales de una misma compañía (Wladimir, 2009), al tiempo que se estima que en la periferia capitalista hay 85 millones de trabajadores directamente empleados en más de 3 mil 500 zonas de procesamiento para la exportación ubicadas en 130 países 
(McKinsey, 2012). El movimiento de capitales, mercancías y fuerza de trabajo acarrea un sinnúmero de resultados no buscados, entre ellos las repercusiones de la crisis sanitaria.

En términos de diferenciación e inequidad social, las paupérrimas condiciones de vida de millones de personas, de los más de 300 millones de desempleados y los millones de hacinados en grandes ciudades, muchos de ellos sin agua potable domiciliada y saneamiento, son caldo de cultivo para la propagación de enfermedades contagiosas. No puede desligarse esta tendencia del acelerado y disruptivo desarrollo de las fuerzas productivas que caracteriza al capitalismo contemporáneo, sustentado en las TIC y la llamada revolución de las tecnociencias. El nivel de desarrollo científico y tecnológico es tan espectacular que en algunos sectores los sistemas productivos corrigen el curso de la producción automáticamente, con algoritmos y bases de datos (Big Data) que trascienden las capacidades de un mortal para darle seguimiento (McQuillan, 2018; Zuboff, 2018). Además de una cuestión de conocimiento aplicado, se trata también de un proceso de apropiación de los avances científicos y tecnológicos, a través de la concentración de patentes por un número cada vez más reducido de corporaciones y potencias imperialistas que operan en los principales sectores económicos (Delgado y Chávez, 2016). Estas corporaciones no sólo concentran las innovaciones, sino que administran su aplicación en su afán de controlar los mercados y maximizar sus ganancias, sin importar sus impactos ambientales ni su utilidad para satisfacer necesidades sociales.

Como corolario, se acentúan las inequidades sociales a niveles y grados progresivamente alarmantes, lo que, entre otras cosas, limita el acceso del grueso de la población a condiciones de vida dignas y de recursos para hacer frente a las contingencias sanitarias. Esta tendencia contradictoria del desarrollo de las fuerzas productivas, que imprime su sello a la modernidad capitalista, se deriva del insaciable afán de ganancias que caracteriza al régimen del capital y que, en la etapa actual del capitalismo, hegemonizada por el capital monopolista, adquiere dimensiones superlativas. Ello, a su vez, hace que el incremento de la acumulación capitalista se aparte progresivamente de la satisfacción de las necesidades sociales y entre en abierta contradicción con la naturaleza, generando rupturas metabólicas que fracturan la resiliencia de los ecosistemas y propician la emergencia de contingencias sanitarias.

Con el avance de la ciencia y la tecnología y su impronta en el desarrollo de las fuerzas productivas, crece también la velocidad con la que el capitalismo 
cambia y la manera como se acentúan sus contradicciones. No es lo mismo una fase del capitalismo basada en la energía de vapor que otra sustentada en la energía atómica. El tipo de maquinaria y equipo exige, entre otras cosas, diferentes recursos naturales y volumen de trabajadores, así como modalidades de expansión del mercado. La fase actual del capitalismo tiene características propias, sin que por ello escape a las tendencias generales. Samir Amin (1990) concibe esta fase, con perspicacia, como la era de los monopolios generalizados. En contraposición al mito o fetiche del «libre mercado» pregonado por la ideología neoliberal, esta fase del capitalismo se distingue por la omnipresencia del capital monopolista. Así lo evidencia el hecho de que «Las mayores compañías del mundo (aquellas con más de mil millones de dólares en ventas anuales) (...) dan cuenta de aproximadamente el 60 por ciento del ingreso, 65 por ciento de la capitalización de mercado, y 75 por ciento de las ganancias [mundiales]» (McKinsey, 2012:21). En las últimas décadas, y ante la falta de inversiones redituables en la esfera productiva, se produce un vuelco hacia la especulación financiera y la financiarización de la economía, creando un capital ficticio sin contraparte material, que acelera las crisis y la inestabilidad económica (Bello, 2006).

El curso contradictorio que sigue el desarrollo de las fuerzas productivas se manifiesta en el sector de salud mediante el acceso a alta y sofisticada tecnología e infraestructura médica de un reducido núcleo de las clases y sectores sociales que pueden pagar medicina privada y, en contrapartida, la exclusión de la gran mayoría de la población del acceso a los servicios de salud por carecer de cobertura médica o contar con cobertura insuficiente. El desarrollo clasista de las fuerzas productivas figura también como causa socioeconómica de las pandemias.

Además de las tendencias intrínsecas al desarrollo capitalista, y de su nivel y expresión particular en el contexto actual de monopolización generalizada, entra en juego el impacto de las políticas neoliberales en el ámbito de la salud. Su relación con las enfermedades es evidente. Mediante el paquete de programas de ajuste estructural, en tanto expresión doctrinaria del neoliberalismo, los gobiernos han optado por dejar en manos del «libre» mercado tareas tradicionalmente reguladas por el Estado, como son la salud pública, el agua potable, la energía eléctrica y la educación. Si en épocas de expansión del capitalismo, desde el siglo XIX y hasta avanzada la década de los 1970, los Estados asumían esas tareas garantizando las condiciones sanitarias y educativas de la fuerza de trabajo requeridas para satisfacer las necesidades de crecimiento económico, 
ahora el aumento de la productividad del trabajo por automatización ha suplantado al trabajo, a grado tal que el Estado capitalista no necesita ocuparse más de esa función.

Que el nivel de desarrollo del capitalismo ha llegado a un estadio de riesgo epidemiológico no es novedad. Esto se sabe desde los 1990, cuando las políticas neoliberales se generalizan hacia la mayoría de los países. Es entonces cuando se toma conciencia de que la multirreferida transición epidemiológica, que suponía que los países desarrollados habían logrado extinguir las enfermedades infecciosas para dedicarse a las cardiovasculares y el cáncer, era un mito (Farmer, 1996; Lewontin y Levins, 2007). Los 1990 fueron escenario de nuevas enfermedades y epidemias, así como el rebrote de viejas enfermedades infecciosas como la pandemia del SIDA, los 403 mil casos de enfermos de criptosporidiasis en Milwaukee en 1993, la fiebre del Nilo con 216 muertes en 2002 en Estados Unidos, o la enfermedad del legionario (Foladori, 2003). A esto se agrega la posibilidad de la introducción premeditada de enfermedades infecciosas como mecanismo de sabotaje o guerra. ${ }^{3}$ Luego del atentado terrorista a las torres gemelas en 2001 muchos países se lanzaron a la construcción de laboratorios de bioseguridad niveles B3 y B4 de alto confinamiento, algunos militares, otros privados, muchos de ellos sin control estatal. No sólo se han levantado dudas acerca de si estos laboratorios incuban bioarmamento, sino que hay evidencias de escape involuntario de agentes patógenos, en algunos casos. Se estima que existen más de 2 mil 300 laboratorios de este tipo a nivel mundial (Peters, 2018).

En el marco de políticas neoliberales, aquellos hechos en lugar de haber llevado al control público de los servicios de salud, condujeron a su privatización. Con ello, las grandes corporaciones farmacéuticas tomaron el control de la investigación y el desarrollo con orientación lucrativa, generalizando las asociaciones públicoprivadas (public-private partnerships) (Foladori, 2005b) y descuidando la investigación de enfermedades infecciosas hasta en tanto se convirtieran en epidemias que garantizaran la búsqueda de vacunas para venderlas compulsivamente a los gobiernos impactados por la parafernalia del miedo publicitado por la Organización Mundial de la Salud (OMS), y regida por las parcerías con la Big Pharma (Hancock, 1998; Boseley, 2002; Horton, 2002). Tal vez algo de esto haya ocurrido con la investigación y el desarrollo de vacunas contra el SARS-CoV-2. Muchos subtipos del

${ }^{3}$ En 1951, durante la guerra de Corea, Estados Unidos creó el Servicio de Inteligencia de Epidemias como mecanismo de prevención. 
virus se encontraban en investigación antes de desatada la pandemia, ${ }^{4}$ aunque la Big Pharma asumió la investigación de vacunas y antivirales después de las declaraciones por la Organización Mundial de la Salud. Ante la posibilidad de acceder a financiamiento rápido y fácil proveniente de gobiernos y fondos filantrópicos, muchos laboratorios y asociaciones de ellos se lanzaron a la investigación de antivirales y vacunas (Lee, 2020), en un momento especialmente propicio para que las diferentes fases de los exámenes clínicos sean acortados o directamente evadidos (Liu, 2020; UiPath, 2020).

\section{La covid-19 y la contradicción capital-trabajo asalariado}

A pocos meses de desatada la pandemia, la relación entre salud y economía cubrió las noticias y las políticas públicas: żaislar a la población para evitar contagios a costa de arruinar la economía?, o żmantener la economía apostando a una limpieza de la población más débil?

Como ninguna de las dos alternativas resulta viable en su forma más radical en un mundo globalizado, la producción, el transporte y la distribución esencial de mercancías siguen funcionando en combinación con diferentes modalidades de confinamiento. Una de las principales preocupaciones de los gobiernos es evitar que colapsen los sistemas de salud pública; situación que para los países periféricos reviste mayor dramatismo aún. Con infectados y muertos el problema se traslada rápidamente de la salud a la economía: la crisis económica ya está presente y se profundiza día a día. En poco tiempo, la principal preocupación para la mayoría de la población es el hambre. A principios de enero de 2020, a un mes del brote de la epidemia, el Banco Mundial estimaba la crisis como equivalente a la de 2008, con continuas actualizaciones pesimistas (Klebnikov, 2020). Tres meses más tarde el Fondo Monetario Internacional pronostica para este año la emergencia de la mayor recesión desde la Gran Depresión de 1929 (Guimón, 2020). Varios gobiernos han establecido medidas de salvamento financiero

\footnotetext{
${ }^{4}$ Existen varios subtipos del virus, de los cuales sólo los A y B tienen relevancia en humanos. Los primeros que se reportaron endémicos para los humanos fueron las HCoV-OC43 y 229E en 1960. En 2004 y 2005 otras variedades fueron identificadas en humanos, las HCoV-NL63 y HKU1; inclusive ha habido epidemias como una con SARS-CoV que producía neumonía en 2002/2003 y que afectó al menos a 8 mil personas; y la MERS-CoV que también producía neumonía (Corman et al., 2018). Todos estos virus venían siendo investigados en muchos de los laboratorios de alta contención en el mundo, algunos de ellos con antecedentes de escape de virus (Peters, 2018).
} 
circunstancial para algunos sectores, cuestión que resulta claramente insuficiente en el corto y mediano plazo.

Mientras mayor es la concentración y centralización del capital, ${ }^{5}$ mayor es el crecimiento del ejército de reserva en proporción al ejército obrero en activo, y mayor también es la distancia en el acceso a la riqueza producida de la clase capitalista frente a los miles de millones de personas que componen las clases trabajadoras. El capital ha generado una desbordante masa de trabajadores sumergida en las filas de la informalidad que supera la cantidad de trabajadores en activo y que día con día lucha para sobrevivir en condiciones de pobreza y pobreza extrema (Foster et al., 2011). No debe sorprender que éstos no tengan el colchón de respaldo para soportar el lock out de las políticas de salud de la covid-19 sin trabajar o recibiendo salarios recortados, al tiempo que los dueños de las corporaciones se dedican a especular en la bolsa comprando oro o corporaciones en quiebra (aerolíneas, hoteles, etcétera) y vendiendo acciones a la baja (Randall, 2020). Resulta evidente, en este sentido, que la crisis de salud, al proyectársele en el espejo de las principales contradicciones que caracterizan al sistema capitalista en la actualidad, se manifiesta también como una crisis de la relación capital-trabajo asalariado.

El trabajo asalariado es el rasgo esencial y distintivo de las relaciones capitalistas. Mediante la venta de su fuerza de trabajo la clase trabajadora tiene acceso a una parcela, aunque mínima, de la riqueza social. Pero el trabajo asalariado funge también como la fuente de la ganancia capitalista. La hipótesis que aquî sostenemos es que las repercusiones de la pandemia de la covid-19 trastocan la relación capital-trabajo asalariado de manera irreversible. Ello nos sitúa ante un doble escenario: el inicio de una fase postneoliberal de desarrollo capitalista o la génesis de un proceso de transición hacia otro régimen de organización social. Lo más probable es que ambas salidas se entrecrucen.

La unidad contradictoria de la relación capital-trabajo se expresa en el hecho de que el capital concentra los medios de producción, pero no dispone de la fuerza de trabajo capaz de ponerlos en movimiento. No obstante el enorme avance de la automatización en muchos sectores productivos, aún existen más de 3 mil 300 millones de trabajadores asalariados, que son el indicador más claro

${ }^{5}$ La concentración se refiere a mayores capitales en menos manos, la centralización a la unificación de las actividades en el espacio. Esto último no es contradictorio con las redes mundiales de distribución de productos (i.e. Amazon, AliBaba, etcétera) y debe visualizarse en los servidores digitalizados de la información (granjas de servidores). 
de que el capital todavía necesita de fuerza de trabajo (Organización Internacional del Trabajo, 2019). En el ámbito del trabajo asalariado sucede algo similar: para sobrevivir, estos millones de trabajadores no tienen otra opción que vender su capacidad de trabajo al capital. Ambos polos de la relación capital-trabajo tienen, a pesar de los lazos de interdependencia que los unen, contradicciones derivadas de su particularidad y que se expresan en el ámbito de la lucha de clases. En el caso de la fuerza de trabajo, se trata de dos características esenciales. De un lado, su lucha permanente por mejorar sus condiciones de vida presionando al capital para aumentar los salarios reales y garantizar que los aumentos en la productividad e intensidad del trabajo se traduzcan en un incremento de sus ingresos. Desde mediados de los 1970 esta lucha ha tenido saldos negativos que se materializan en el estancamiento y caída de los salarios reales. De otro lado, una segunda particularidad de la fuerza de trabajo alude a la preocupación de los trabajadores de no caer en el desempleo e integrarse a las filas del ejército de reserva laboral para el capital que, por su propia naturaleza, tiende a ejercer una presión a la baja en los salarios; situación que, por la esencia misma de la relación capital-trabajo, resulta inevitable.

Con respecto al capital, existen de igual modo particularidades que lo sitúan en franca oposición al trabajo, siendo también, en este caso, dos las fundamentales. La primera alude al hecho de que todo aumento de la productividad, extensión e intensidad del trabajo conlleva a un aumento de las ganancias, que es el leitmotiv del capital para producir. Si en este proceso se puede lograr una disminución o estancamiento de los salarios reales, tanto mejor para el capital. La segunda particularidad se refiere a que el aumento de la productividad a nivel individual de la empresa significa un aumento de sus ganancias extraordinarias, pero al expandirse la innovación al resto de la rama y a la economía en su conjunto, se incrementa la composición orgánica del capital y con ello se propicia también, paradójicamente, una caída de la tasa general de ganancia.

La crisis desencadenada por la covid-19 no sólo se propaga a la esfera económica en sus manifestaciones más abiertas y palpables, sino que penetra de manera disruptiva e irreversible en el corazón mismo del sistema capitalista: la contradicción capital-trabajo.

Todos los analistas económicos y financieros concuerdan en que la crisis de salud ha provocado una crisis económica (Guimón, 2020). La caída de las acciones, aunque de forma desigual para los diferentes sectores económicos, es un dato ampliamente difundido por los medios de comunicación. Adicionalmente, 
es vox populi que las políticas de confinamiento han acabado con sectores económicos completos, como las aerolíneas, las cadenas de restaurantes y hoteles, las agencias de viaje y turismo. En términos globales los índices de las bolsas de valores de los países pierden valores monetarios tan pronto se anuncia un aumento del confinamiento en un país, o ganan puntos como resultado de una mínima liberación del confinamiento. Cuando ocurren crisis financieras las monedas pierden valor frente al oro, plata u otro tipo de activo físico. El oro sigue cumpliendo la función de medida de valor, medio de pago y medio de atesoramiento, aunque haya perdido su función como medio de circulación, cuestión que no es ignorada por los bancos centrales que venden sus reservas a corporaciones o bancos privados para apoyar sectores económicos debilitados por la crisis o cubrir gastos fiscales, quedando con ello la moneda nacional más frágil y aumentando la inequidad internacional.

Con la pandemia de la covid-19 se espera un incremento masivo del desempleo, cuya pérdida se estima en 25 millones de puestos de trabajo (ILO, 2020) que se sumarán a los 300 millones de desempleados que había hacia finales de 2019 (World Bank, 2019), lo que a su vez se traducirá en una significativa caída en el volumen de valor, plusvalor, y ganancia a escala mundial. En virtud de las profundas e intrincadas diferencias entre pobres, desempleados, parados, ocupados de tiempo parcial y completo - todos sujetos a vaivenes por empresa y sector económico-, resulta difícil vislumbrar la posibilidad de salidas colectivas a la crisis. De aquí que el desenlace más probable de esta amalgama de situaciones sea la violencia, el saqueo y la desesperación generalizada, a lo cual las fuerzas del orden serán incapaces de responder eficazmente y, mucho menos, de controlar. ${ }^{6}$

Pero si una característica del contexto capitalista actual directamente asociada a la crisis de salud es el desempleo y la reducción del valor generado, otra característica aún más significativa para nuestros fines analíticos es el alto nivel de desarrollo científico y tecnológico alcanzado por las fuerzas productivas. Este desarrollo posibilita la automatización generalizada de los procesos laborales. En esta perspectiva, es importante consignar que existe la posibilidad

${ }^{6}$ La corrida hacia la compra de armas en Estados Unidos es un botón de muestra (Kaufman, 2020; Perez, 2020); al igual que las revueltas civiles por alimentos, y, en el otro extremo, empresas de construcción ofreciendo bunkers subterráneos a la élite de la burguesía para defenderse de un futuro incierto tanto en términos ambientales como sociales; otro ejemplo es el aumento de la violencia doméstica (Nações Unidas Brasil, 2020). 
técnica de avanzar hacia la integración automatizada de todas las cadenas de valor. Esto último funge como una característica clave de la llamada industria 4.0, que reduce los tiempos muertos no sólo en los procesos de producción discretos - algo logrado desde tiempo atrás-, sino en las cadenas de producción como un todo.

Desde la perspectiva empresarial, la crisis de la covid-19 ha agregado a la histórica lucha política de la clase obrera la fragilidad biológica de su organismo, que contrasta con la máquina. No es de sorprender que ya esté aumentado la compra de equipo sofisticado para ampliar y profundizar la automatización (Robotic Process Automation, RPA) (Dejtiar, 2020; Field y Murphy, 2020; Zhang, 2020).?

La consecuencia lógica de este proceso es, por un lado, un desempleo masivo, ya no temporal sino permanente derivado del implacable avance de la automatización y, por el otro, un aumento de la productividad del trabajo en aquellas ramas que logren automatizarse y apropiarse de ganancias extraordinarias. Este proceso dará paso a una mayor concentración y centralización del capital (i.e. una monopolización generalizada); cuestión que, al incrementar la composición orgánica del capital, tenderá a acentuar la caída tendencial de la tasa de ganancia. Con ello, dejará de ser novedad la frecuencia y concatenación de las crisis, como también el cada vez más exiguo impacto contratendencial de los repuntes en la productividad.

En medio de esta vorágine, signada por la inseguridad, la violencia y el caos civil, se perfilan dos escenarios contrastantes que comienzan a ser analizados y debatidos al seno de la izquierda. Por un lado, el empleo de las fuerzas del orden o del expediente de la militarización para controlar a aquellos que se ubiquen fuera de la contradicción capital-trabajo (desempleados, desahuciados, y marginados en general) y, por el otro, la instauración de un ingreso universal para paliar la situación incorporando a millones de personas como consumidores, aunque no como productores y, por tanto, integrándolos sólo marginalmente a la contradicción capital-trabajo. Lo importante a subrayar es que ninguna de estas opciones tiene futuro. Ambas muestran la inviabilidad del sistema para retornar a la «normalidad» o anormalidad preexistente.

${ }^{7}$ "Crisis can be sort of a catalyst or can speed up changes that are on the way - it almost can serve as an accelerant, said Arun Sundararajan, an NYU Stern School of Business professor researching how digital technologies transform society» (Field y Murphy, 2020). 


\section{A manera de conclusión}

La pandemia de la covid-19 ha tomado al mundo por sorpresa, sea por la velocidad de expansión, por la alta tasa de morbilidad y mortalidad, o por muchos otros factores. Cierto es que el crecimiento de la población y su concentración urbana facilitan los contagios. Pero también es cierto que el nivel de desarrollo científico y tecnológico debiera permitir medidas de monitoreo y prevención, así como de curación, mucho más eficientes. El problema no es ni de exceso de gente ni de falta de conocimientos y tecnología. El problema es social.

Las relaciones capitalistas han profundizado una serie de desequilibrios, tanto socioambientales como científico-tecnológicos, que propician la emergencia de crisis como la desencadenada por la covid-19. Al manifestarse como una pandemia, la crisis de salud hace referencia a un problema humano en sentido amplio, que afecta a la humanidad como un todo y que se diferencia de las crisis regionales o locales, étnicas, de género, de empleo, de refugiados, fronterizas, financieras y muchas otras, que sólo afectan a determinados grupos sociales o espacios geográficos.

El grado de desigualdad social imperante, fincado en condiciones extremas de pobreza, desempleo y precariedad laboral configura un ambiente poco propicio para el desenvolvimiento de una sociedad saludable. La homogeneización de los ecosistemas no configura un entorno propicio para la resiliencia ambiental. La ciencia y la tecnología guiadas por el beneficio mercantil no constituyen tampoco un ambiente adecuado para un avance de las fuerzas productivas que favorezca a las mayorías, no obstante posibilite satisfacer las demandas de una minoría. La expansión de las TIC relega las relaciones personales directas, convirtiendo al símbolo virtual en más fiable que la confianza personal y dando base a las fake news que inundan la información cotidiana, y a la Big Data que ordena la información científica con algoritmos a los que nadie puede dar seguimiento.

Muchas de estas causas, que aluden al contexto social en el que se incuba la pandemia, han sido ampliamente documentadas y analizadas en la literatura, donde se encuentran también diversos análisis acerca de sus consecuencias más palpables y desembozadas. Las numerosas quiebras y cierres temporales de empresas pequeñas y medianas, incluyendo a grandes corporaciones como es el caso de las aerolíneas, las cadenas hoteleras y restauranteras y otras empresas turísticas, dan cuenta de la severidad y alcances de la crisis económica en curso, 
así como de los desafíos e incertidumbres que plantea. Algunas de las medidas políticas para reducir o paliar los impactos de la crisis arremeten contra la «diplomacia» democrática, a grado tal que muchos analistas sociales y políticos llaman la atención acerca del inminente riesgo de que modalidades autoritarias acaben por enraizarse en la estructura del Estado capitalista.

El abanico de temas analizados es cada vez más amplio y variado. Abarca desde el dilema de transitar hacia modalidades educativas y de consumo virtuales, hasta la propuesta de generalizar el ingreso universal, pasando por reflexiones acerca la crisis del imperialismo estadounidense y los cambios que se perfilan en la geopolítica global.

Como apuntamos al principio, el propósito de este artículo es contribuir a la discusión en curso sobre las causas e implicaciones de la crisis de la covid-19, desde un ángulo particular: los efectos disruptivos de la pandemia sobre la relación capital-trabajo. Para ello, hemos venido argumentando que la crisis sanitaria está detonando una crisis que trasciende la esfera económica y que está empujando al sistema capitalista hacia un punto de no retorno.

En relación con esto último cabe hacer hincapié acerca de dos tendencias en curso. La primera se refiere a la fuerte presión que existe, por el efecto disruptivo de la pandemia, para que las empresas automaticen sus procesos productivos. Esta presión deriva de la enorme cantidad de empresas que están quebrando y de las demandas de paro, por riesgo de contagio, en las que aún se labora. La reducción del trabajo asalariado implica, a su vez, reducción del plusvalor generado y, por ende, caída de las ganancias. Ante ello, la única alternativa previsible es avanzar por la senda de la automatización, es decir, la sustitución radical del trabajo vivo por el trabajo muerto. Si bien esto sólo agrava el problema en el largo plazo, no deja de ser la salida empresarial individual más viable en el corto plazo. Este proceso es tecnológicamente factible en la gran mayoría de los sectores productivos. Si la llamada Revolución industrial 4.0 no se ha extendido más, no es porque falte la tecnología, sino porque resulta más barato contratar asalariados. Sin asalariados disponibles, la producción de equipo y su abaratamiento para implantar la industria 4.0 allí donde no alcance todas las etapas, o no esté siquiera instalada, será un hecho. En el corto plazo esto posibilitará contrarrestar, en esas industrias, la reducción de la masa de plusvalor con un aumento de su tasa. En el mediano y largo plazos ello implica un paso muy significativo en la dirección de trascender el régimen del capital. Al negar al trabajo vivo el sistema niega también su única fuente de riqueza y crecimiento y se niega, por tanto, a sí mismo. 
La segunda tendencia impacta en el polo opuesto de la relación capitalista: el capital. Se trata de un impulso hacia una mayor concentración y centralización. Basta consignar al respecto la cantidad de empresas que día con día entran en quiebra, incluyendo a sectores económicos enteros o la caída de las acciones, para anticipar que pocos grandes capitales que invirtieron en oro tienen información privilegiada para vender y comprar acciones; según las alzas y bajas de las bolsas, serán los triunfadores y comprarán a precio de remate las empresas en quiebra. Cabe agregar que el capital no sólo explota como clase de manera más o menos unificada a los obreros, sino que, paralelamente, propicia crecientes disputas y confrontaciones entre las distintas fracciones de las clases que integran la sociedad burguesa. Se trata también de una tendencia presente desde la década de los 1990, cuando el sector financiero y los títulos de propiedad pasaron a comandar el mercado, arrebatando ganancias a los sectores productivos y estafando con ventas de mercancías a futuro. El impacto de la covid-19 resulta particularmente disruptivo en el contexto capitalista actual, signado como se planteó en el primer apartado por la omnipresencia del capital monopolista.

En medio de las incertidumbres que plantea la crisis de la covid-19 hay una certeza en la que todos los analistas coinciden: el mundo no será igual antes y después de la pandemia. Por su impacto disruptivo y el contexto en el que se despliega, el virus tendrá una repercusión letal e irreversible sobre la relación capital-trabajo. El escenario que se vislumbra apunta hacia el inicio de una fase postneoliberal de desarrollo capitalista y la eventual génesis de un proceso de transición hacia otro régimen de organización social. Los tiempos y la forma en que esto ocurra depende de la manera como evolucionen los conflictos sociales y el curso que siga la lucha de clases a escala global.

\section{Referencias}

Amin, Samir (1990), "El comercio internacional y los flujos internacionales de capitales», en Samir Amin, Emmanuel Arghiri, Charles Bettelheim y Christian Palloix (dirs.), Imperialismo y comercio internacional: el intercambio desigual, México, Siglo XXI Editores.

Bello, Walden (2006), «The capitalist conjuncture: over-accumulation, financial crises, and the retreat from globalisation», Third World Quarterly, 27(8), pp. 1345-1367. 
Boseley, Sarah (2002), "Unhealthy influence|Guardian daily comment», The Guardian, en www.guardian.co.uk

Brown, Peter J. (1987), «Microparasites and Macroparasites», Cultural Anthropology, 2(1), pp. 155-171.

Corman, Victor M., Doreen Muth, Daniela Niemeyer y Christian Drosten (2018), "Hosts and sources of endemic human coronaviruses», en Margaret Kielian, Thomas C. Mettenleiter y Marilyn J. Roossinck (dirs.), Advances in virus research, London, Academic Press, pp. 163-188.

Dachary, César y Stella Arnaiz (2002), Globalización, turismo y sustentabilidad, Jalisco, Centro Universitario de la Costa/Universidad de Guadalajara.

Dejtiar, Fabian (2020), "Is coronavirus pandemic accelerating the digitalization and automation of cities?», ArchDaily, en https://www.archdaily.com/936064/ is-coronavirus-pandemic-accelerating-the-digitalization-and-automation-ofcities

Delgado Wise, Raúl (2013), «The migration and labor question today», Monthly Review, 64(9), pp. 25-38.

(2017), «El capital en la era de los monopolios generalizados: apuntes sobre el capital monopolista", Observatorio del Desarrollo, 6(18), pp. 48-58.

Delgado Wise, Raúl y Mónica Chávez Elorza (2016), «iPatentad, patentad!!: apuntes sobre la apropiacióndel trabajo científico por las grandes corporaciones multinacionales», Observatorio del Desarrollo, 5(15), pp. 21-28.

Farmer, Paul (1996), «Social inequalities and emerging infectious diseases», Emerging Infectious Diseases, 2(4), pp. 259-269.

Field, Hyden y Mike Murphy (2020), "covid-19 will herald an automation boom», Protocol newsletters, en https://www.protocol.com/automation-boom-caused-by-coronavirus

Foladori, Guillermo (2003), «La privatización de la salud. El caso de la industria farmacéutica», Revista Internacional de Sociología, 61(34), pp. 33-64.

(2005a), «La enseñanza de Katrina», Rebelión, en http://www.rebelion. org/noticia.php? $\mathrm{id}=19789$ (2005b), "The challenge of infectious diseases to the biomedical paradigm", Bulletin of Science Technology \& Society, 2(25), pp. 145-158.

Foster, John Bellamy, Robert W. McChesney y R. Jamil Jonna (2011), «The global reserve army of labor and the new imperialism», Monthly Review, 63(6).

Guimón, Pablo (2020), «El FMI pronostica para este año la mayor recesión desde la Gran Depresión de 1929», El País, en https://elpais.com/economia/(2020)-04-09/el-fmi- 
preve-que-la-pandemia-provocara-el-mayor-impacto-en-la-economia-desde-lagran-depresion.html

Hancock, Trevor (1998), "Caveat partner: reflections on partnership with the private sector», Health Promotion International, 13(3).

Horton, Richard (2002), «WHO: the casualties and compromises of renewal», Lancet (London, England), 359(9317), pp. 1605-1611.

International Labour Organization (2020), «Almost 25 million jobs could be lost worldwide as a result of covid-19, says ILO», en http://www.ilo.org/global/about-the-ilo/ newsroom/news/WCMS_738742/lang--en/index.htm

Jarus, Owen (2020), "20 of the worst epidemics and pandemics in history», LiveScience, en https://www.livescience.com/worst-epidemics-and-pandemics-in-history. html

John Hopkins Coronavirus Resource Center (2020), "Covid-19 Map», Johns Hopkins Coronavirus Resource Center, en https://coronavirus.jhu.edu/map.html

Kaufman, Elinore (2020), «Opinion | Please, Stop Shooting. We Need the Beds», The New York Times.

Klebnikov, Sergei (2020), «World Bank forecasts weakest global economic growth since the financial crisis», Forbes, en https://www.forbes.com/sites/sergeiklebnikov/(2020) /01/09/world-bank-forecasts-weakest-global-economic-growth-since-the-financial -crisis/

Lee, Jaimy (2020), «These 19 companies are working on coronavirus treatments or vaccines - here's where things stand", MarketWatch, en https://www.marketwatch. $\mathrm{com} /$ story/these-nine-companies-are-working-on-coronavirus-treatments-orvaccines-heres-where-things-stand-(2020)-03-06

Lewontin, Richard C. y Richard Levins (2007), Biology under the influence: dialectical essays on ecology, agriculture, and health, New York, Monthly Review Press.

Liu, Angus (2020), «The White House is pushing FDA to clear Fujifilm's Avigan for covid-19. Should the agency obey?», FiercePharma, en https://www.fiercepharma.com/ pharma/white-house-asks-fda-to-approve-fujifilm-s-avigan-for-covid-19-should -agency-follow

McKeown, Thomas (1991), The origins of human disease, Oxford, Blackwell.

McKinsey Global Institute (2012), "The world at work: jobs, pay, and skills for 3.5 billion people», en https://www.mckinsey.com/ /media/McKinsey/Featured\%20Insights/ Employment\%20and\%20Growth/The\%20world\%20at\%20work/MGI\%20Global_ labor_Full_Report_June_2012.ashx 
McQuillan, Dan (2018), «People's councils for ethical machine learning», Social Media + Society, 4(2).

Nações Unidas Brasil (2020), "Chefe da ONU alerta para aumento da violência doméstica em meio à pandemia do coronavírus», ONU Brasil, en https://nacoesunidas.org/chefeda-onu-alerta-para-aumento-da-violencia-domestica-em-meio-a-pandemia-do -coronavirus/

Organización Internacional del Trabajo (2019), «El gran problema del empleo en el mundo: las malas condiciones de trabajo», en http://www.ilo.org/global/aboutthe-ilo/newsroom/news/WCMS_670577/lang--es/index.htm

Perez, Jamie (2020), "Gun sales spike during covid-19 pandemic, retailers see ammo shortage», Channel3000, en https://www.channel3000.com/gun-sales-spike -during-covid-19-pandemic-retailers-see-ammo-shortage/

Peters, A. (2018), «The global proliferation of high-containment biological laboratories: understanding the phenomenon and its implications», Revue Scientifique et Technique de l'OIE, 37(3), pp. 857-883.

Randall, David (2020), «Wall Street week ahead: investors look for buys as virus fears crush travel stocks», Reuters.

Rubin, Isaac Ilich (1972), Essays on Marx's Theory of Value. Detroit, Black and Red.

Sarewitz, Daniel y Roger Pielke (2001), «Extreme events: a research and policy framework for disasters in context», International Geology Review, 43(5), pp. 406-418.

UiPath (2020), «Automating covid-19 data testing with RPA for vaccine», UiPath. Responding to covid-19 together, en https://www.uipath.com/resources/covid-automations/ viable-vaccine-for-covid

Wladimir, Andreff (2009), "Outsourcing in the new strategy of multinational companies: foreign investment, international subcontracting and production relocation", Papeles de Europa, 18, pp. 5-34.

World Bank (2019), "Unemployment, total (\% of total labor force) (modeled ILO estimate)», en https://data.worldbank.org/indicator/sl.uem.totl.zs

Zhang, Jan (2020), "Coronavirus will force manufacturers to enhance automation, digitalization", Control Engineering, en https://www.controleng.com/articles/ coronavirus-will-force-manufacturers-to-enhance-automation-digitalization/

Zuboff, Shoshana (2018), The age of surveillance capitalism: the fight for a human future at the new frontier of power, New York, PublicAffairs. 